\title{
The missing link: The parental voice in Bring Your Own Device (BYOD) programs
}

\author{
Therese Keane $^{1} \mathbb{D} \cdot$ William F. Keane $^{1}$
}

Received: 12 September 2021 / Accepted: 17 January 2022 / Published online: 21 February 2022

(c) The Author(s) 2022

\begin{abstract}
This paper reports on the parental perspective on one school's implementation of a Bring Your Own Device (BYOD) Program to ensure students had access to a personalized computer. Often studies of one computer to one student (1:1) Programs focus on students and or teachers while parent compliance in the Program is assumed. Consequently, there is limited literature that explores parental perceptions and concerns, and subsequent decision-making process, in the implementation of a BYOD Program. The aim of this study was to document the parental voice in the implementation of one such BYOD program. This case study focused on one large co-educational school with 130 parents completing a questionnaire that provided both quantitative and qualitative responses. This enabled an exploration of the effect of the BYOD Program as reported by parents themselves, as well as the examination of a range of related issues, such as textbook use, the financial burden and choice of device. The findings provided insight, through the lens of the parents, into how the BYOD Program was deployed. Three trends emerged from the study: parents clearly expected some kind of trade-off in terms of expenditure, they clearly wanted reassurances that their investment was worthwhile and that the devices would be used for improving learning. Further research needs to be undertaken about parental perspectives, expectations, and concerns of BYOD Programs.
\end{abstract}

Keywords BYOD $\cdot$ Parental concerns $\cdot$ Parental expectations $\cdot$ Textbooks $\cdot$ 1:1 programs $\cdot$ Mobile computing

Therese Keane

tkeane@swin.edu.au

William F. Keane

wkeane@swin.edu.au

1 School of Social Science, Media, Film and Education, Swinburne University of Technology,

Hawthorn, Melbourne, Victoria, Australia 


\section{Introduction}

For more than four decades schools have grappled with the implementation and use of computers in the classroom. The situation in the first decade of this century was that, while some secondary schools had implemented one to one Programs (1:1) the ratio of one computer to one student - the majority had not. In Australia, substantial funding was committed to deliver the Digital Education Revolution (DER) to provide all senior secondary students with access to their own personal computer (Keane \& Keane, 2020; Rudd et al., 2007). However, once the funding ceased and the DER was discontinued, school leaders had to make decisions on the future of a 1:1 Program in their schools. Some schools implemented a Bring Your Own Device (BYOD) Program (Janssen \& Phillipson, 2015) which, while shifting the cost to parents, was designed to keep those costs manageable.

Following a successful pilot program, a large co-educational school in Victoria offered an optional BYOD Program to their school community. This paper examines parental expectations and concerns relating to this one school's implementation of a BYOD Program.

\section{Literature review}

Over the past 40 years schools have chosen to implement computing in the curriculum through a variety of methods, highly dependent on the type of technology available at any given time. Initially, schools deployed computers in special purpose rooms which quickly became computer laboratories. Over time, as technology became mobile and affordable, some schools opted for highly regulated one computer to one student $(1: 1)$ Programs. These programs typically, with top-down structures in place, incorporated a specified device and model, procurement, software, warranty, insurance, and a help desk on site. All students involved in highly regulated 1:1 Programs were expected to work within the parameters the school had outlined as part of their program. The first 1:1 Program was in Victoria, Australia, in a high fee-paying private Independent school in the early 1990s (Loader, 2015). The significant cost to implement a 1:1 Program meant that the adoption of these programs was far from universal.

Given the changing landscape of technology usage, affordable technology and budgetary constraints imposed on schools, the emergence of other types of 1:1 Programs evolved. In Australia, the interest and rise of BYODs (Bring Your Own Device) coincided with the cessation of the Government funded Digital Education Revolution (Johnson et al., 2015). BYOD is defined as consumer technology that is portable, has the ability to connect to networks and is owned by the student. In a BYOD Program students bring a mobile device of their choice, while typical devices for these programs include iPads, tablet devices, laptops and notebooks (Hopkins et al., 2017). In essence, BYOD Programs foster a 1:1 student to computer ratio with limited regulation and cost to the school (Johnson et al., 2015). There are essentially two types of BYOD Programs, one that is BYOD 
Specified Device, whereby the school stipulates the types and models of the device to purchase and it is left to the parents to either purchase it through their own means or through the school. The advantage of this type of BYOD Program is that all students have a similar device or limited range of devices which, in turn, limits inequalities amongst students, and provides consistency and stability for teachers. The second type of BYOD Program is where the school provides the minimum specifications of a device so that a student can bring any type of device to school and the student is not disadvantaged with a slow and nonfunctioning computer. The school only provides networking infrastructure and limited technical assistance (Janssen \& Phillipson, 2015).

Several factors have influenced the uptake of 1:1 Programs in schools. The benefits for students have included the possibilities of improving learning outcomes and preparing them for twenty-first century skills (Keane et al., 2016) and increased student engagement, and increased interaction between students (Elliott-Dorans, 2018). For teachers the benefits have included the shift of focus of teaching to learning, so that classrooms are empowering learners. For schools, the most significant factor is the cost shifting so that parents are responsible for purchasing and maintaining devices (Parsons \& Adhikar, 2016).

The key stakeholders in any 1:1 Program in schools are teachers, students, and parents (Adams, 2021; Adhikari et al., 2017; Liao et al., 2017). While in highly regulated programs, parents are not generally provided a voice, in a BYOD Program, parents along with the student, make an informed decision about the device they will be using. Despite the important role parents' play in their children's education (Goodall, 2016; Hoover-Dempsey \& Sandler, 1997), there is limited literature about parental views and perspectives of 1:1 BYOD Programs (Hopkins et al., 2017; Keane \& Keane, 2018; Ortiz et al., 2011). The significance of parental engagement emerges from the sociocultural theory of learning whereby parents model learning which influences children's attitudes towards learning and schooling (Goodall, 2016). While this modelling extends to include parent/school engagement, parents find this challenging when it comes to their children's use of technology (Bond, 2019). Ortiz et al. (2011), for example, suggested that a child's views about computers are strongly influenced by their parents and parents can be somewhat uncertain about the benefits of computers on learning. Moreover, parent concerns are sometimes a product of their own lack of experience using computers in schools (Keane \& Keane, 2018). Stemming from this uncertainty, appropriate use of technology in class is a common concern shared by many parents (Adams, 2021). Time wasting is also a concern for parents who want reassurances that their children use computers for learning when in class (Keane \& Keane, 2018; Tallvid et al., 2015). Some parents believe that, when not directed by a teacher, students play games, use the internet, access social media or email during class time (Aagaard, 2015; Courtois et al., 2014; Fried, 2008; Gong \& Wallace, 2012; Hatakka et al., 2013; Kontkanen et al., 2017; Pamuk et al., 2013) and are therefore worried that this inattention will lead to poorer academic performance (Burak, 2012; Carrier et al., 2015; Sana et al., 2013). According to Lei and Zhao (2008, p. 116), parents were "less positive" about 1:1 Programs, if they thought their children were distracted by non-learning activities on their devices 
or that other skills such as handwriting would erode (Lei \& Zhao, 2008). Additionally, a family's financial situation can also have a bearing on the provision of equipment provided (Adams, 2021).

This study seeks to further understand the relationship between parents and BYOD Programs in secondary schools through obtaining perspectives about these programs. The analysis was guided by the following overarching research questions that emerged out of the issues presented in the Literature Review:

RQ1: What are parents' attitudes and perspectives towards BYOD Programs?

RQ2: What considerations took place when purchasing a device?

RQ3: How is the device being managed in the classroom?

\section{Methodology}

\subsection{Research context}

This study was undertaken in one large co-educational metropolitian secondary school located in Melbourne, Australia with approximately 2400 students across Years 7-12 with gender parity. The school had a socio-economic profile which placed it at the 61st percentile of the Index of Community Socio-Educational Advantage (ICSEA), the national measure to determine socio-economic advantage. The comparative wealth of the school population is concentrated in the middle two quartiles. In other words, there are fewer families who are either poor or wealthy. The school piloted an optional BYOD Program aimed at Years 7 and 10 in the year prior to offering the program across the school. Following the pilot, it was decided that it would run a non-compulsory BYOD Program the year after across Years 7-12. Even though the BYOD Program was non-compulsory, the school strongly encouraged all parents to participate, however there were parents who did not want to and therefore did not purchase a device for their children.

The findings are presented in one case study which provided insights into the program and discussed the challenges in implementing a non-compulsory, but strongly encouraged BYOD Program at one school.

\subsection{Participants}

All parents from the school were invited to the take part in the study. Out of 1346 parents, a total of 151 parents accepted the invitation to take part in this study. However, the final data pool consisted of 130 parents who voluntarily completed the online questionnaire. Ethics permission was sought prior to the study from Swinburne University and the Catholic Education Melbourne and subsequently permission was also sought through the Principal. Written consent on voluntary and anonymous participation was then obtained from the parent participants. 


\subsection{Research instruments}

A mixed methodology was employed comprising of a questionnaire to provide quantitative and qualitative responses. This enabled an exploration of parental views on BYOD Programs and the decisions explaining their participation, the influence of device choice, and their perspectives on how they believed the devices are being used in the classroom. The findings from the research is presented in a case study and according to Dul and Hak (2008, p. 4) "a case study is a study in which a) one case (single study)...in their real life context are selected, and b) scores obtained from these cases are analysed in a qualitative manner."

\subsection{Questionnaire}

After the BYOD Program had been running for almost eight months, a questionnaire was sent to all parents regardless of whether or not they participated in the BYOD Program. The questionnaire sought both quantitative and qualitative responses. There were 17 questions delivered electronically to parents. Parents completing the questionnaire remained anonymous and could not be identified. The questionnaire was mainly qualitative in nature and involved a series of open-ended response questions directly relating to the research questions listed earlier. Free text entries from the parent questionnaires were read repeatedly to enable the coding and categorization of responses, then counted to enable quantitative comparisons. Participants were given an option to provide further comments. Entries to survey tick data were compiled to provide quantitative data. This qualitative data analysis method was informed by the work of Boyatzis (1998) and Bogdan and Biklen (1998). The questions asked of the participants centred around the following:

- Factors affecting BYOD Program participation

- The decision-making process of purchasing the device

- The type of device purchased

- The age of the device

- Perception of classroom use of the devices

- Benefits of a BYOD Program

\section{Discussion}

Of the 130 parents who answered this questionnaire, $82.31 \%$ indicated they took part in the BYOD program. When invited to explain the reason for their participation, there were six overwhelming themes from the responses:

- They didn't want their child to miss out;

- The program was recommended by the school;

- They placed high value on this program; 
- The development of digital literacy skills/ positive contribution to learning;

- Their children wanted to be part of it;

- The benefits of having seamless integration between home and school;

In considering the responses overall, a seventh theme emerged:

- They were tentative about the program however they wanted more research but were prepared to commit.

Table 1 shows the themes identified along with a sample of comments from parents.

Parents expressed their views in a variety of ways. Some were simply curious about the program while others expressed the view that computer use is important for the future. Some parents focused specifically on the potential for the improvement in their child's learning. Despite the generally positive responses given by those who chose to participate, there was some disquiet expressed by a number of respondents. A small number of parents felt that they had been forced into participating in the program, citing implied pressure from the school. As one parent put it, "I don't feel we 'chose' to take part, we were made to feel we had to." More significantly, a new theme emerged from the responses as can be seen in Table 2. These parents, while being prepared to commit to the program, were unsure about it:

In contrast, those who did not choose to be part of the BYOD Program cited cost as the major factor with the issue of cost linked to the continued use of textbooks. While one very small group of parents expressed the view that textbooks were easier to work with than devices - and did not support the introduction of devices for learning- others complained about the additional cost of a device on top of prescribed textbooks. This continued requirement for significant numbers of textbooks was a source of complaint for several parents. Additionally, some parents also highlighted the non-compulsory nature of the program, expressing doubt that the school had appropriately communicated their long-term plans for a BYOD Program. One parent gave a detailed account of their reasons for not participating in the program complaining that having come from an interstate school:

We needed to buy $\$ 1,800$ worth of textbooks and stationery for 2 students. The quantity of stationery on the booklist indicated that most of the work that the children did would be handwriting, not computer-based work. To purchase 2 devices on top of this for the children to take to school was unreasonable when the booklists pointed to the fact that the devices would not be used. When the children and I were given a tour of the school we were told that we wouldn't need to participate in the program as there were plenty of class sets of computers that could be used if required.

This parent highlighted an issue for the school that there were contradictions in the BYOD Program. Having an optional program meant that textbooks and stationery remained on the booklist. This meant - as several parents pointed out - that the cost of the device was not defrayed by reducing costs in areas such as textbooks. 


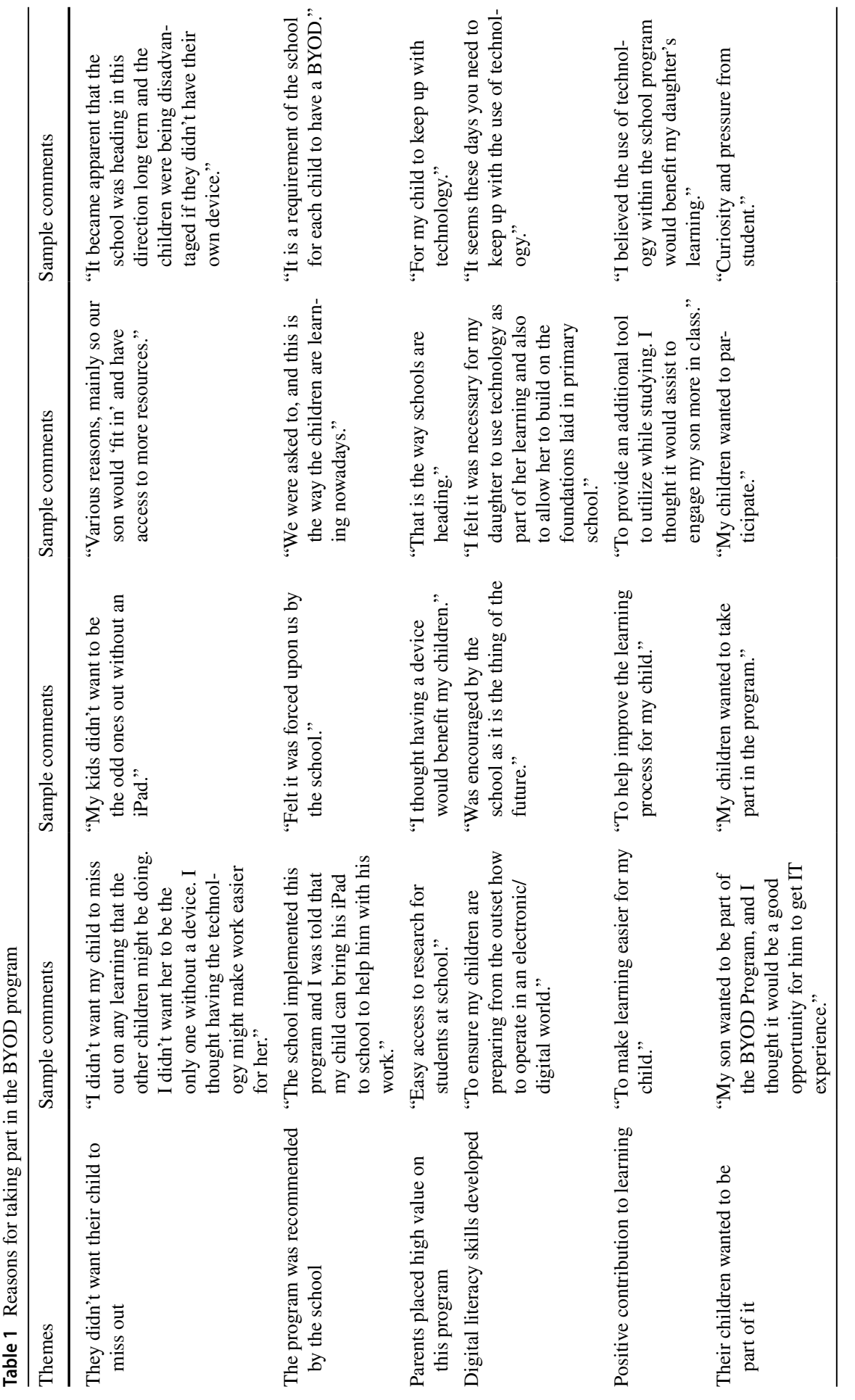




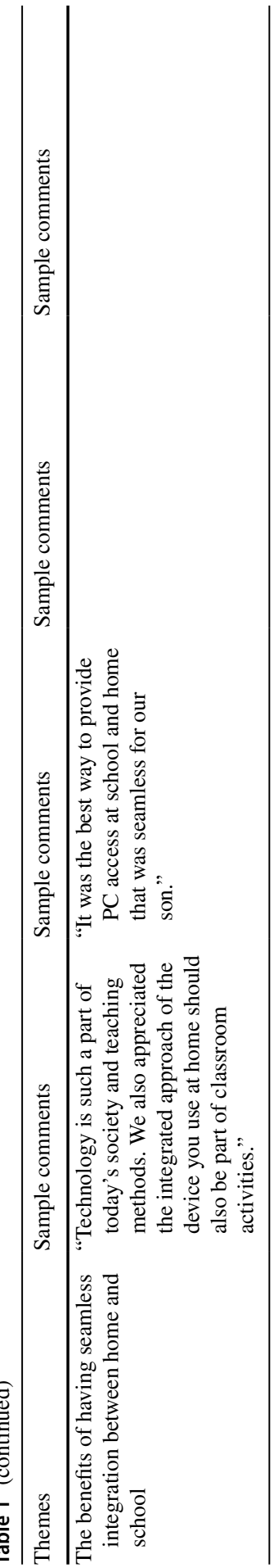

第 Springer 


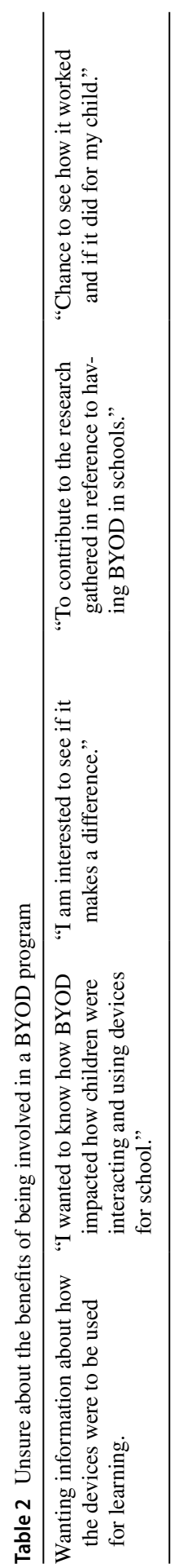


Moreover, retaining textbooks and stationery, ensured that there would be mixed messaging as to how the devices would be integrated into the curriculum.

There were similarities in the concerns expressed by those who did not join the program and those who joined but expressed some reservations about it. Both groups would have preferred to be better informed about the consequences of a BYOD Program, especially as the nature of the program meant that, necessarily, parents and students needed to be heavily involved, particularly in the initial stages. In fact, the school made parent and student involvement a virtue in their communications to parents, highlighting that a BYOD program allowed students to use the device with which they are most familiar. This element of student choice is clearly reflected in the survey results with $70 \%$ of parents indicating that their child was involved in the purchase decision.

For all the advertised freedoms, there were constraints on the choice of device. For many, considerations of price dictated the device purchased, followed by its size, weight and portability. Other factors that were influential included brand loyalty, especially amongst Apple users, and whether parents felt that a particular brand would be suitable for educational, and classroom needs (see Table 3 for examples of comments). Some parents indicated they did considerable research before settling on a particular device whereas others stated that the choice of device was entirely left up to their children. Many parents who expanded on their reasons, noted that they based their choice on prior experience with devices. In explaining their choice one parent touched on a range of factors, "How it would perform, how relevant it would be in the classroom, how light it was to carry and if it would fit on the desk at school, the amount of memory it had and the ability to update it, and the price." These were factors that were considered when purchasing a device:

- Cost;

- Size, weight and portability;

- Brand loyalty;

- Already having a device;

- Research undertaken about a particular device;

- Student choice.

The choice of device was varied with $47 \%$ purchasing an iPad and $36 \%$ choosing a laptop. In terms of the age of the device, $33 \%$ of parents purchased a new device. $26 \%$ stated their device was less than one year old while $36 \%$ stated that their device was less than 2 years old. A potential pitfall of a BYOD Program was highlighted by $41 \%$ of the parents reporting that the devices provided were more than a year old. Having a range of devices of variable age in a classroom seemed likely to create challenges for teachers in implementing the BYOD Program. Overwhelmingly, 79\% of devices used for the BYOD Program were purchased specifically for student use (some students already had a device from primary school).

The school did not stipulate which device to purchase, but rather provided a list of specifications to enable participation at different price points to minimise the cost to parents. In weighing up the benefits of a BYOD Program versus a program with 


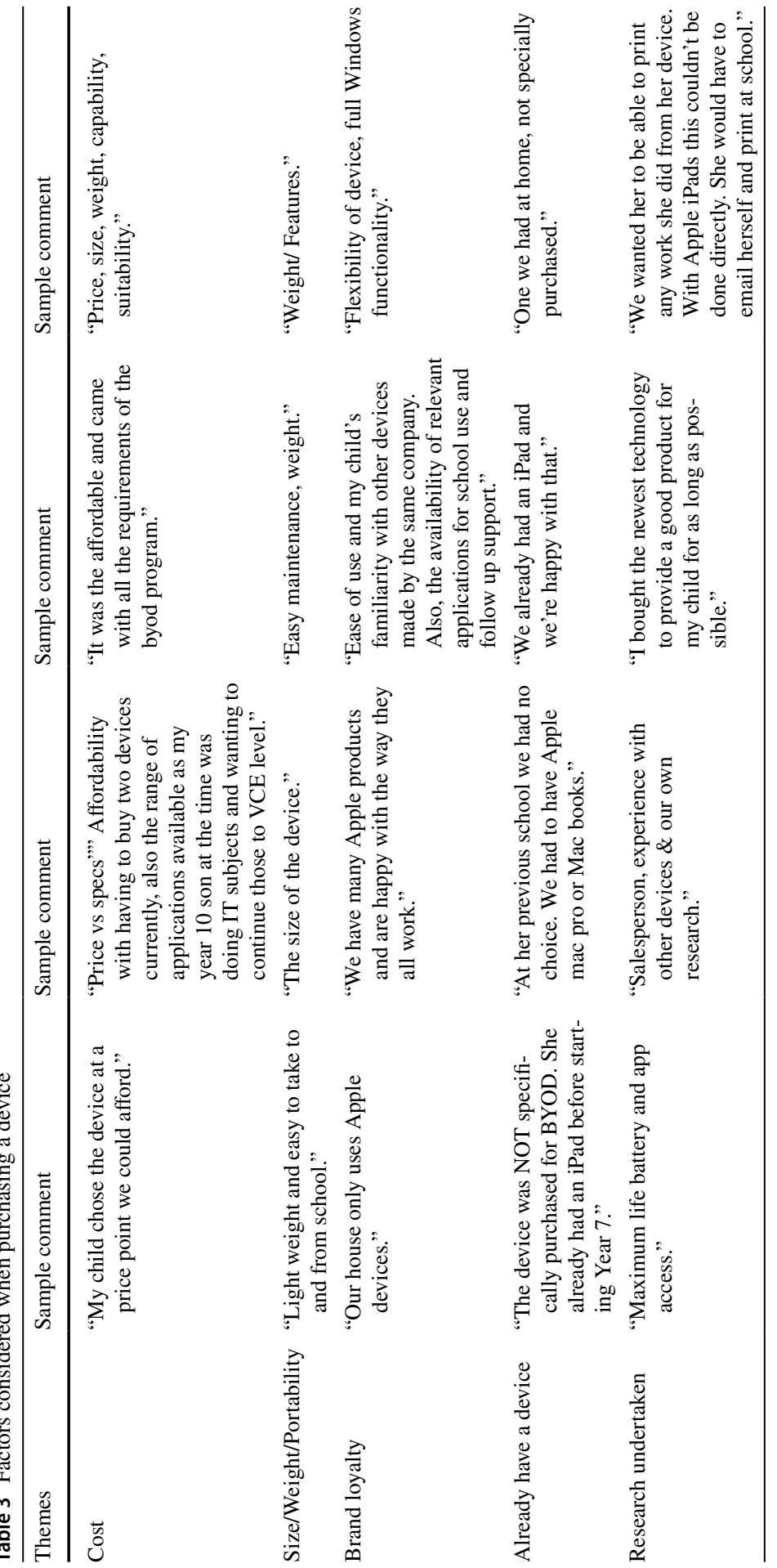




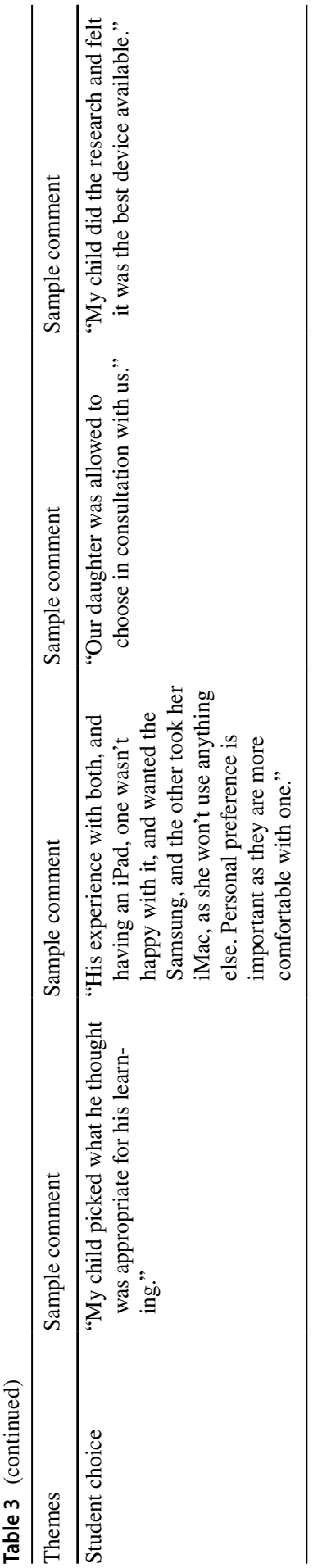


a common device, the parents viewed price, flexibility and student preference as the key benefits of a BYOD Program. One parent articulated advantages in a BYOD Program in these terms:

Cost I suppose. Had we been required to purchase an iPad for example for each child (next year we will have three at the school) the cost would have been prohibitive, and it may not have suited our older son doing IT subjects.

Despite the cost advantages inherent in a BYOD Program, $61 \%$ of parents would have preferred a 1:1 Program that prescribed a common device. In addition, $78 \%$ of parents would have been prepared to purchase a nominated device from the school as they were acutely aware that having many different types of devices in a classroom caused many challenges for teachers, students and parents. In addition, several parents believed that having a common device would provide significant advantages for the teaching and learning program, with one arguing, "It's a benefit to the teachers when helping students if everyone had the same device." It seemed to many parents to be self-evident that one platform or standard operating system would make it more consistent for all and easier and more effective for the teachers. Moreover, as one parent explained:

Some parents are not familiar with technology so are unable to offer the necessary support to their son/daughter. If it is one device, I would expect all teachers are familiar enough with the device to be able to provide the necessary support to students.

Another major issue to emerge was equality. The BYOD Program, designed in part to ensure that a device was affordable, was also seen as divisive. The benefits of having a common device was summed up by another parent in this way:

It's a bit a like a uniform, no student looks different, has any advantage or disadvantage - it's a level playing field. Particularly with technology, which is constantly changing/upgrading, our concern is being able to keep up with the latest (as will be our son's wish). Whereas if the school prescribed the device, this would not be an issue.

One point of contention that emerged again and again was the issue of textbooks. Parents were firmly of the view that students should not have to carry textbooks as well as a device and they were critical of the lack of electronic textbooks. The expense and weight of textbooks was an issue which they had expected the BYOD Program to address. Parents wanted e-books, partly because of cost but also because of the weight of school bags. Some parents complained that e-books they had purchased did not work on the chosen device, an unintended, if unsurprising, consequence of a BYOD Program.

Despite concerns about the pilot program, especially including their frustrations about textbooks, the parents were generally supportive of a program which aimed to ensure that students had devices.

In fact, only one of the parents who responded to the survey believed that the program should end because: 
I don't think it's necessary or improves the education being received. In fact, I think it can have several negative affects including creating points of difference between students because they cannot afford the 'best' brand and also reading from electronic sources has been proven to damage eyesight. I would be extremely disappointed if our school replaced texts with devices.

For the most part, rather than wanting the program to wind up, parents were firmly of the view that the devices needed to be better and more extensively used, and that teachers should, "Actually use the devices for most subjects."

Overall, $80.81 \%$ of parents reported that they were satisfied with how the device was used at the school. While a solid figure, it is worth noting that nearly one in five parents were not satisfied with the usage of the device, suggesting significant room for improvement. When asked how the devices were being used a third of the parents replied that they did not really know, while another $8 \%$ reported that the devices were hardly used at all. Communication by the school before the implementation of the program was somewhat vague about how the devices would be used. This lack of knowledge of device usage by parents is consistent with other research in the area (Keane \& Keane, 2018) and highlights the importance of schools communicating the purpose and progress of an implementation.

It was apparent that, once the program was underway, there was not much effort made to explain how the devices were used in class. This lack of knowledge led some parents to question their choices:

We regret the decision to purchase a laptop. After a number of instances, we feel an iPad would have been a better option. More portable, cheaper, better able to be protected from damage. I wish we had known about how the devices would be used. Searching the internet and access to ebooks seems primary purpose.

One parent summed up perhaps the key issue with a BYOD Program in this way:

I don't believe having so much choice has helped the teachers or the students, rather I believe it has restricted what can happen in class because there isn't a uniform platform. I think in the junior campus there should be a common device and then in the senior campus as students' subjects vary, then they can have a choice of the device that best suits their needs. I think more support is needed for teachers too as some don't encourage the use of technology in learning.

When asked about ways to improve the BYOD Program, a number of parents responded with suggestions about having a compulsory program and/or prescribing a specific device. Others offered suggestions about easing the financial burden or felt that the school could provide improved Information Technology (IT) infrastructure. Examples of comments can be seen in Table 4.

A key suggestion for improvement was better communication from the school about how the devices were being used. A common plea was that "Teachers use devices more often. At the moment they are often carried to class and not used." This need for better communication with parents is consistent with earlier findings 


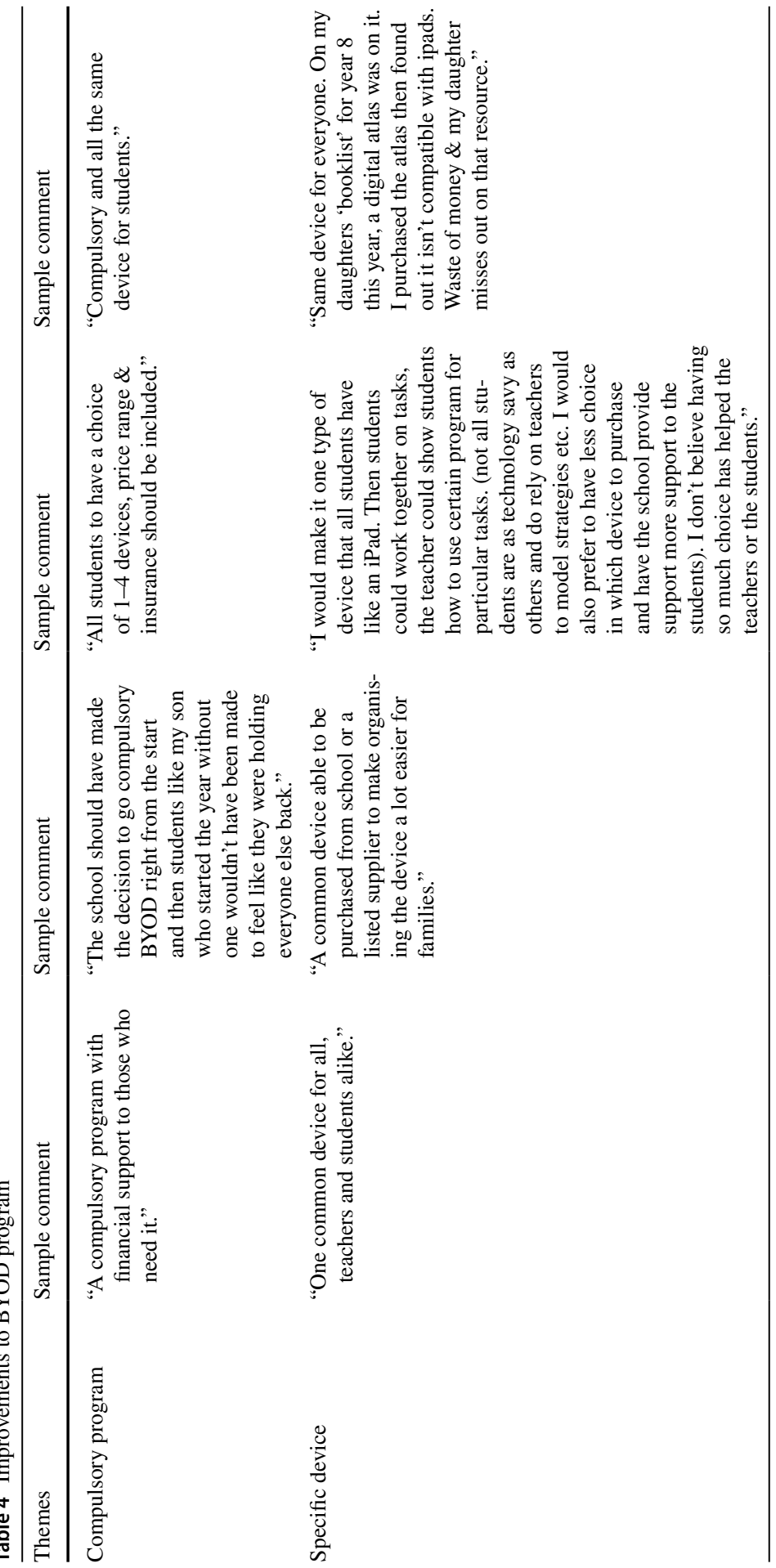




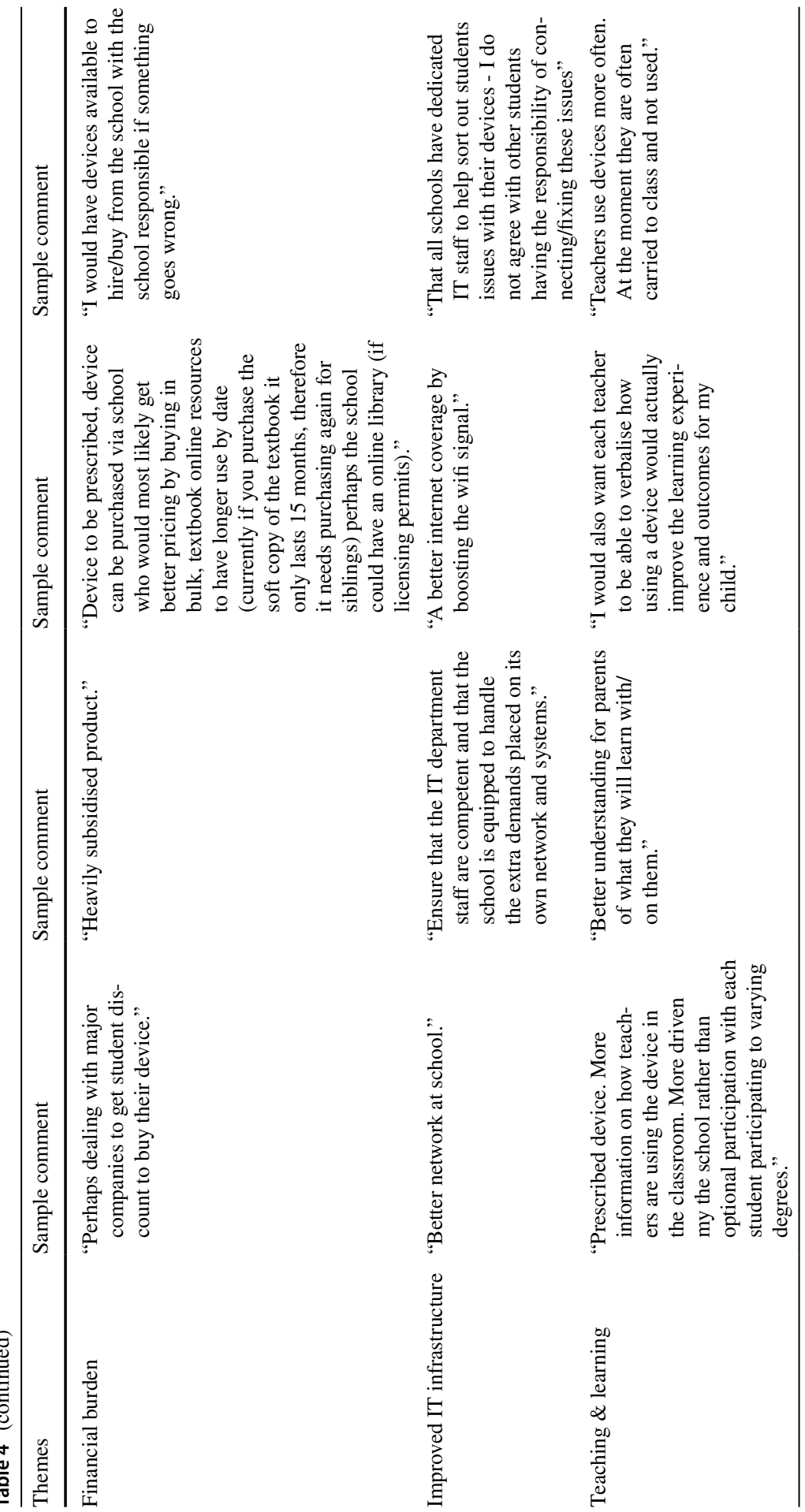




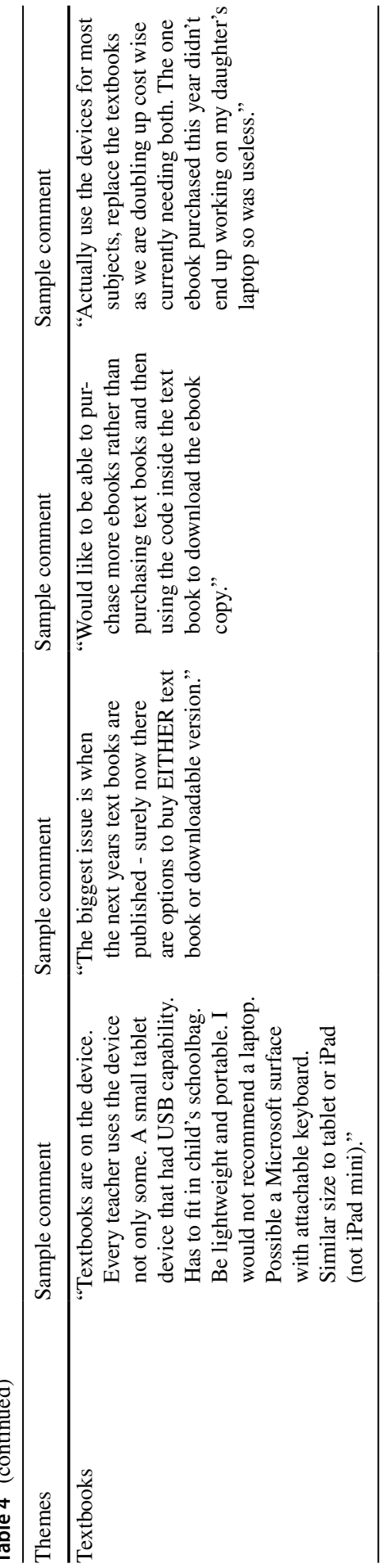


by Keane and Keane (2018) that good communication is important for the successful implementation of a 1:1 Program.

\section{Conclusion}

As Janssen and Phillipson (2015) suggest, for many schools the implementation of a BYOD Program was to smooth the transition from a situation where the devices were provided by DER funding to one where the parents pay for the device. By design a BYOD Program, rather than a program specifying one particular device, reduces costs to parents by allowing them to source the cheapest possible device or to utilise one that they already possess.

However, going down the BYOD path creates problems difficult to resolve. By implementing a BYOD Program - and a voluntary one at that - the school was unable or unwilling to reduce costs in other areas. This was reflected in the commentary about the costs - and bulk - of textbooks. Therefore, BYOD which was supposed to be a lower cost solution than a designated device, came to be seen as an additional cost. Parents clearly expected at least some kind of trade off in terms of expenditure.

The textbook issue had other ramifications as well. By having devices and textbooks, the school was sending mixed messages about the nature of the program. There was little clarity for parents about how the devices were to be used in class. This lack of clarity was a constant theme in the responses from parents who complained much more about the lack of use of the devices that they did about overuse. Parents, for the most part, expressed a preference for a compulsory program with a designated device to enable clarity of classroom use. There was frustration, too, that well into the program, many teachers seemed unable to articulate how the devices were being used in the classroom. However, the very nature of the BYOD Program was likely to be the cause of this apparent lack of transparency. Having multiple devices in the classroom would, of necessity, make planning for digital technology use highly problematic. Moreover, the retention of textbooks on the booklist suggests a conservative approach to learning and would likely act as a disincentive to change.

If the BYOD Program was implemented to smooth the transition from DER funding of devices to families bearing the cost themselves, then it was only partly successful. Overwhelmingly, the response from parents was positive in their support of the concept of having devices in the classroom but they clearly wanted reassurance that their investment was worthwhile and that the devices would be used for improved learning. Instead, in justifying the benefits of the program, the school explained that "BYOD provides students and teachers with the opportunity to move towards personalised learning, differentiated teaching strategies and a focus on the learning; not the device." The telling aspect of this is the transitional nature being described. The benefits depicted here were not apparent to the parents. In shifting costs of devices to parents - as happens in all schools with 1:1 
Programs - it was clear that parents wanted more from the partnership with the school than a mitigation of costs; they were looking for an understanding about how the use of devices would improve the learning for their children.

Authors' contributions Therese Keane: made substantial contributions to the conception or design of the work; the acquisition, analysis, interpretation of data; drafted the work or revised it critically for important intellectual content, approved the version to be published.

William Keane: made substantial contributions to the interpretation of data, drafted the work or revised it critically for important intellectual content, approved the version to be published.

Funding Open Access funding enabled and organized by CAUL and its Member Institutions. The authors did not receive support from any organization for the submitted work.

Data availability Availability of data is upon request.

Code availability Not Applicable.

\section{Declarations}

Ethics approval Ethics approval was sought through Swinburne University and the Catholic Education Office in Melbourne. Ethics was approved from both institutions.

Competing interests The authors have no relevant financial or non-financial interests to disclose.

Open Access This article is licensed under a Creative Commons Attribution 4.0 International License, which permits use, sharing, adaptation, distribution and reproduction in any medium or format, as long as you give appropriate credit to the original author(s) and the source, provide a link to the Creative Commons licence, and indicate if changes were made. The images or other third party material in this article are included in the article's Creative Commons licence, unless indicated otherwise in a credit line to the material. If material is not included in the article's Creative Commons licence and your intended use is not permitted by statutory regulation or exceeds the permitted use, you will need to obtain permission directly from the copyright holder. To view a copy of this licence, visit http://creativecommons.org/licen ses/by/4.0/.

\section{References}

Aagaard, J. (2015). Drawn to distraction: A qualitative study of off-task use of educational technology. Computers \& Education, 87, 90-97. https://doi.org/10.1016/j.compedu.2015.03.010

Adams, H. R. (2021). Bring your own device (BYOD) and equitable access to technology. In A. M. Dawkins (Ed.), Intellectual freedom issues in school libraries (pp. 123-124). ABC-CLIO, LLC.

Adhikari, J., Mathrani, A., \& Scogings, C. (2017). A longitudinal journey with BYOD classrooms: Issues of access, capability and outcome divides. Australasian Journal of Information Systems, 21. https://doi. org/10.3127/ajis.v21i0.1693

Bogdan, R., \& Biklen, S. K. (1998). Qualitative research for education: An introduction to theory and methods (3rd ed.). Allyn and Bacon.

Bond, M. (2019). Flipped learning and parent engagement in secondary schools: A south Australian case study. British Journal of Educational Technology, 50(3), 1294-1319. https://doi.org/10.1111/bjet.12765

Boyatzis, R. E. (1998). Transforming qualitative information: Thematic analysis and code development. Sage Publications.

Burak, L. (2012). Multitasking in the university classroom. International Journal for the scholarship of Teaching and Learning, 6(2), 1-12 Retrieved from https://vc.bridgew.edu/mahpls_fac/74/. Accessed 12 Sep 2021. 
Carrier, L. M., Rosen, L. D., Cheever, N. A., \& Lim, A. F. (2015). Causes, effects, and practicalities of everyday multitasking. Developmental Review, 35, 64-78. https://doi.org/10.1016/j.dr.2014.12.005

Courtois, C., Montrieux, H., De Grove, F., Raes, A., De Marez, L., \& Schellens, T. (2014). Student acceptance of tablet devices in secondary education: A three-wave longitudinal cross-lagged case study. Computers in Human Behavior, 35, 278-286. https://doi.org/10.1016/j.chb.2014.03.017

Dul, J., \& Hak, T. (2008). Case study methodology in business research. Butterworth-Heinemann.

Elliott-Dorans, L. R. (2018). To ban or not to ban? The effect of permissive versus restrictive laptop policies on student outcomes and teaching evaluations. Computers \& Education, 126, 183-200. https://doi.org/ 10.1016/j.compedu.2018.07.008

Fried, C. B. (2008). In-class laptop use and its effects on student learning. Computers \& Education, 50(3), 906-914. https://doi.org/10.1016/j.compedu.2006.09.006

Gong, Z., \& Wallace, J. (2012). A comparative analysis of iPad and other M-learning technologies: Exploring students' view of adoption, potentials, and challenges. Journal of Literacy and Technology, 13(1), 2-29 Retrieved from http://www.literacyandtechnology.org/uploads/1/3/6/8/136889/jlt_vol13_2.pdf\# page $=2$. Accessed 12 Sep 2021.

Goodall, J. (2016). Technology and school-home communication. International Journal of Pedagogies and Learning, 11(2), 118-131. https://doi.org/10.1080/22040552.2016.1227252

Hatakka, M., Andersson, A., \& Grönlund, A. (2013). Students' use of one to one laptops: A capability approach analysis. Information Technology \& People, 26(1), 94-112. https://doi.org/10.1108/09593 841311307169

Hoover-Dempsey, K. V., \& Sandler, H. M. (1997). Why do parents become involved in their children's education? Review of Educational Research, 67(1), 3-42. https://doi.org/10.3102/00346543067001003

Hopkins, N., Tate, M., Sylvester, A., \& Johnstone, D. (2017). Motivations for 21st century school children to bring their own device to school. Information Systems Frontiers, 19(5), 1191-1203. https://doi.org/10. 1007/s10796-016-9644-Z

Janssen, K. C., \& Phillipson, S. (2015). Are we ready for BYOD? A systematic review of the implementation and communication of BYOD pograms in Australian schools. Australian Educational Computing, 30(2) Retrieved from http://journal.acce.edu.au/index.php/AEC/article/view/54. Accessed 12 Sep 2021.

Johnson, L., Adams Becker, S., Estrada, V., \& Freeman, A. (2015). NMC horizon report:2015 K-12 edition. Retrieved from http://www.ctdinstitute.org/sites/default/files/file_attachments/2015-nmc-horizonreport-k12-EN.pdf. Accessed 12 Sep 2021.

Keane, T., \& Keane, W. F. (2018). Parents' expectations, perceptions and concerns when schools implement a 1:1 program. Education and Information Technologies, 23(4), 1447-1464. https://doi.org/10.1007/ s10639-017-9671-5

Keane, T., \& Keane, W. F. (2020). A vision of the digital future - government funding as a catalyst for 1 to 1 computing in schools. Education and Information Technologies, 25(2), 845-861. https://doi.org/10. 1007/s10639-019-09988-y

Keane, T., Keane, W. F., \& Blicblau, A. S. (2016). Beyond traditional literacy: Learning and transformative practices using ICT. Education and Information Technologies, 21(4), 769-781. https://doi.org/10.1007/ s10639-014-9353-5

Kontkanen, S., Dillon, P., Valtonen, T., Eronen, L., Koskela, H., \& Väisänen, P. (2017). Students' experiences of learning with iPads in upper secondary school-a base for proto-TPACK. Education and Information Technologies, 22(4), 1299-1326. https://doi.org/10.1007/s10639-016-9496-7

Lei, J., \& Zhao, Y. (2008). One-to-one computing: What does it bring to schools? Journal of Educational Computing Research, 39(2), 97-122. https://doi.org/10.2190/EC.39.2.a

Liao, C. C., Cheng, H. N., Chang, W.-C., \& Chan, T.-W. (2017). Supporting parental engagement in a BYOD (bring your own device) school. Journal of Computers in Education, 4(2), 107-125. https://doi.org/10. 1007/s40692-017-0085-6

Loader, D. (2015). Transforming education: The introduction of laptops to the classroom. Independence, 40(2), 58-59. https://doi.org/10.3316/informit.579880828942173?casa_token=A4S6T6KxZj 4AAAAA:1i7RSqhoieNSsQsIjk3IG2BbEkgXHswZwOHQ0y0btaRTsCsviBC3KynDfXOqXnkXr wDpMKqdoSObLg

Ortiz, R. W., Green, T., \& Lim, H. (2011). Families and home computer use: Exploring parent perceptions of the importance of current technology. Urban Education, 46(2), 202-215. https://doi.org/10.1177/00420 85910377433 
Pamuk, S., Çakır, R., Ergun, M., Yılmaz, H. B., \& Ayas, C. (2013). The use of tablet PC and interactive board from the perspectives of teachers and students: Evaluation of the FATIH project. Educational Sciences: Theory \& Practice, 13(3), 1815-1822. https://doi.org/10.12738/estp.2013.3.1734

Parsons, D., \& Adhikar, J. (2016). Bring your own device to secondary school: The perceptions of teachers, students and parents. Electronic Journal of E-Learning, 14(1), 66-80 Retrieved from https://eric.ed. gov/?id=EJ1099110. Accessed 12 Sep 2021.

Rudd, K., Smith, S., \& Conroy, S. (2007). A digital education revolution: Election 2007 policy document. Australian Labor Party, Australia. Retrieved from https://parlinfo.aph.gov.au/parlInfo/search/display/ display.w3p;query=Id:\%22library/partypol/DQXO6\%22. Accessed 12 Sep 2021.

Sana, F., Weston, T., \& Cepeda, N. J. (2013). Laptop multitasking hinders classroom learning for both users and nearby peers. Computers \& Education, 62, 24-31. https://doi.org/10.1016/j.compedu.2012.10.003

Tallvid, M., Lundin, J., Svensson, L., \& Lindström, B. (2015). Exploring the relationship between sanctioned and unsanctioned laptop use in a 1: 1 classroom. Educational Technology \& Society, 18(1), 237-249 Retrieved from https://www.jstor.org/stable/jeductechsoci.18.1.237. Accessed 12 Sep 2021.

Publisher's note Springer Nature remains neutral with regard to jurisdictional claims in published maps and institutional affiliations. 